\title{
Testing the core of sandwich panels with square shear specimen
}

\author{
S. Grimm \& J. Lange \\ Institute for Steel Construction and Materials Mechanics, Technical University of Darmstadt, Darmstadt, \\ Germany
}

\begin{abstract}
This paper presents the results of research on the determination of shear stiffness and strength of curved sandwich panel's core material. A new test setup was developed to determine the material parameters of the core. Furthermore, the material properties orthogonal to the longitudinal axis of linearly manufactured sandwich panels were examined. The findings are relevant for the three-dimensional modelling of shell structures made of curved sandwich panels. The new test setup can be used for the assessment of the global load-bearing behaviour of plane panels, which are loaded by torsion or shear stresses resulting from suspended facades, as well as the local load-bearing behaviour of sandwich panels with openings or point loads.
\end{abstract}

\section{INTRODUCTION}

Today lightweight sandwich panels are a common solution for roof and wall claddings. Due to their excellent weight to load ratio, their good heat insulation, their high load-bearing capacity as well as the economical manufacturing and erection process, sandwich panels are used frequently. Their load-bearing behaviour is usually analysed with beam models following their longitudinal axis, which also is the direction of production (x-axis) of linearly manufactured sandwich panels. Therefore, shear-test were developed for sandwich panels to determine the stiffness and strength of the core in the y-z-plane.

The linear manufacturing process of sandwich panels usually limits the possible building cubature to rectangular shapes. In an interdisciplinary project, architectural, civil engineering and mechanical engineering institutes of Technical University of Darmstadt developed a concept to build shell structures out of linearly manufactured uniaxial curved sandwich panels. The project shows that arched sandwich panels have a high potential regarding the load-bearing capacity.

This paper presents the results of a research project on the shear stiffness and strength of the core material of curved sandwich panels. A new test setup was developed to determine the material parameters of curved panels. Furthermore, it can be used to assess these properties in directions differing from the longitudinal axis of the panels. In this context, these material properties are needed to model the three-dimensional behaviour of sandwich shell structures. In a further study, the material properties differing from the longitudinal axis of linearly manufactured sandwich panels were examined. The material properties of the core deviating from the longitudinal axis are for instance relevant for the assessment of the global loadbearing behaviour of plane panels, which are loaded by torsion or shear stresses resulting from suspended facades, as well as the local load-bearing behaviour of sandwich panels with openings or point loads. 


\section{SQUARE SHEAR TESTS}

Square shear tests are for instance described by Jungbluth and Berner (1986) as well as Davies (2001). They were used as an alternative setup to the established four-pointbending shear test, which is described in EN 14509 annex A.3. Jungbluth and Berner (1986, Bild 7.23) compared the results of these different shear test, also taking into account three rail shear tests as well as dynamic three-point bending tests. Their results show that the shear stiffness and strength evaluated with the square shear tests most reasonably correspond to the values determined with the four-point-bending tests. Furthermore, square shear tests avoid an influence of indentations resulting from the support and loading of the specimen in the four-point-bending test. They have increasing importance since the depth of today's sandwich panels can easily reach up to $300 \mathrm{~mm}$. Nevertheless, studies during the development of the new test setup showed an important weakness of the existing square test setups.

\subsection{Assumptions of shear tests on square-shaped specimen}

A small specimen is cut from the panel, which has to be square-shaped in the plane of interest. On the four sides of the square stiff plates, either from steel (Jungbluth \& Berner 1986) or wood (Davies 2001) are attached. The specimen is loaded diagonally by tensile or compression forces. Shear stresses and strengths can be determined based on the measured load and displacement as well as the geometry of the specimen, pure shear stresses assumed.

The shear strain can be calculated as:

$$
\gamma=\frac{\sqrt{2} u}{l}
$$

where $u=$ is the displacement; $l=$ length of the square sides.

The shear stress can be calculated as:

$$
\tau=\frac{P}{\sqrt{2} A}
$$

where $P=$ is the load; $A=$ area resulting from the length of the square sides and the depth of the specimen.

\subsection{Assessment on the square shear test setup}

Due to the deviations of the shear strengths determined by using the square tests or the fourpoint bending tests, the load-bearing of the square test setup used by Jungbluth and Berner was studied in two-dimensional finite element models.
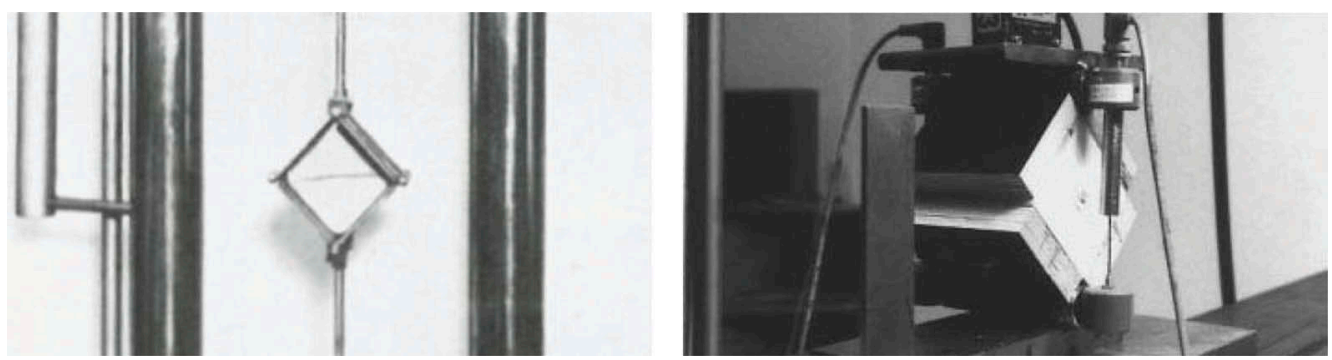

Figure 1. Square tests by Jungbluth \& Berner (1986, Bild 7.21) and Davies (2001, Fig. 13.4). 


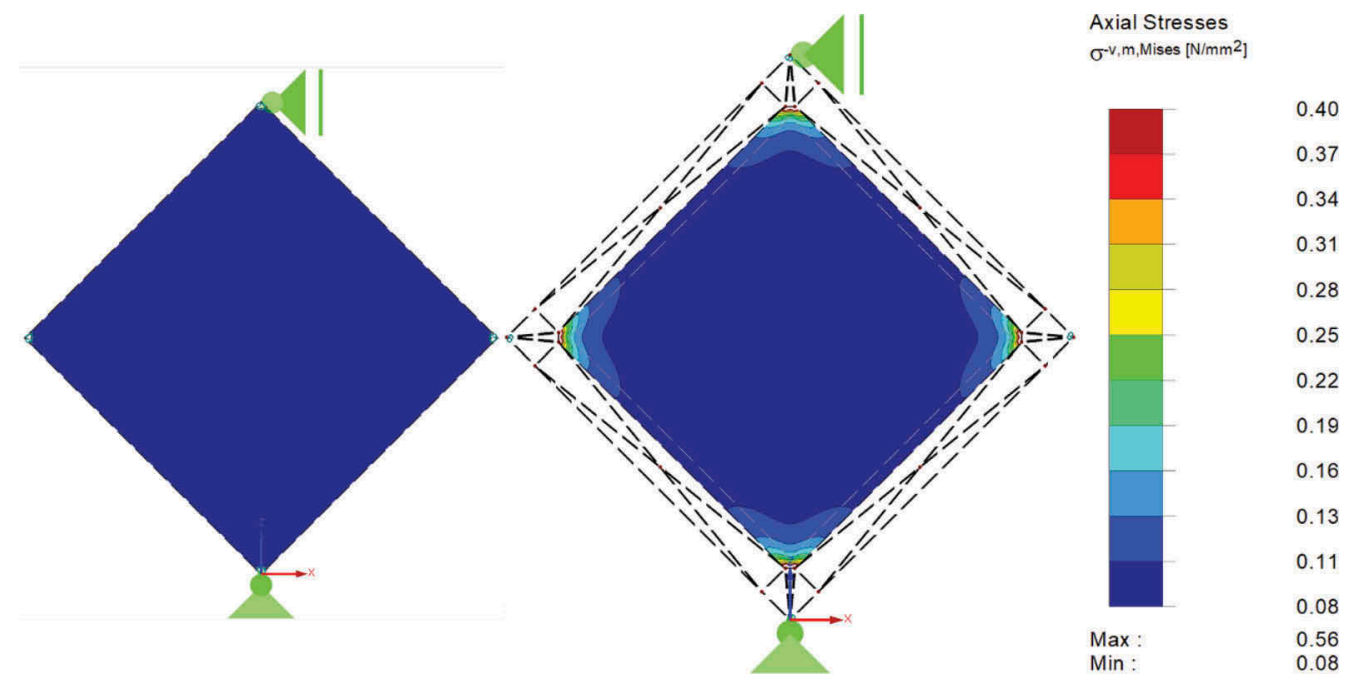

Figure 2. Results of the numerical models - plate thickness of $0 \mathrm{~mm}$ (left) and $20 \mathrm{~mm}$ (right).

The specimen with a length, height and thickness of $100 \mathrm{~mm}$ was modelled using shell elements. Only the core itself was modelled using an ideal-elastically orthotropic material law. Since the shear modulus was $3.0 \mathrm{~N} / \mathrm{mm}^{2}$ for all directions, the Poisson's ratio was set to 0.25 according to Kurpiela (2013). The Young's modulus for all directions was set to $3.0 \mathrm{~N} / \mathrm{mm}^{2}$ as well. The steel plates where modelled with a framework of rigid beams, which have a hinged connections in their edges (see Figure 2). In order to avoid numerical problems the edges of the specimen where rounded by a radius of $2 \mathrm{~mm}$.

The models were loaded by a diagonal tensile force of $1000 \mathrm{~N}$ and evaluated according to Equation (1) and (2). Figure 2 shows the resulting von-Mises stresses. On the left, the results of a dimensionless hinged bordering frame are shown. The specimen on the right is restrained by plates with a thickness of $20 \mathrm{~mm}$. The von-Mises stresses are given in Figure 2 since they take into account the shear stresses as well as the normal stresses. The results show that a pure shear stress state can only be assumed for a test setup with a frame without thickness but with infinite bending stiffness, like the rigid beams in the finite element model on the left. The eccentricity of the hinges causes additional normal stresses in the edges of the specimen that affect the results of the evaluation.

The evaluation of models with growing thickness or eccentricities of the hinges showed unrealistic high values for the shear modulus of the core material. Figure 3 shows the ratio of the evaluated and modelled shear modulus for different thicknesses of frame plates. The hinges were modelled in the centroid of the plates.

It can be seen that the dimensions of the restraining plates affect the validity of the assumptions on which the evaluation in Equation (1) and (2) are based. Technically, it is not possible to design a frame without any eccentricity of the hinges, which equally meets the requirement of a high bending stiffness compared to the core material. Therefore, a hinged frame, which is able to carry the expected loads, will lead to a shear modulus that is approximately 15 to 20 percent higher than the actual material parameter, based on the theoretical results. This also matches to results of the comparison of Jungbluth and Berner (1986, Bild 7.23).

\subsection{Development of the new shear test setup}

Based on the results of the numerical study a revised test setup was developed. The setup is intended to comply with the formulated restrictions of minimum thickness and high bending 


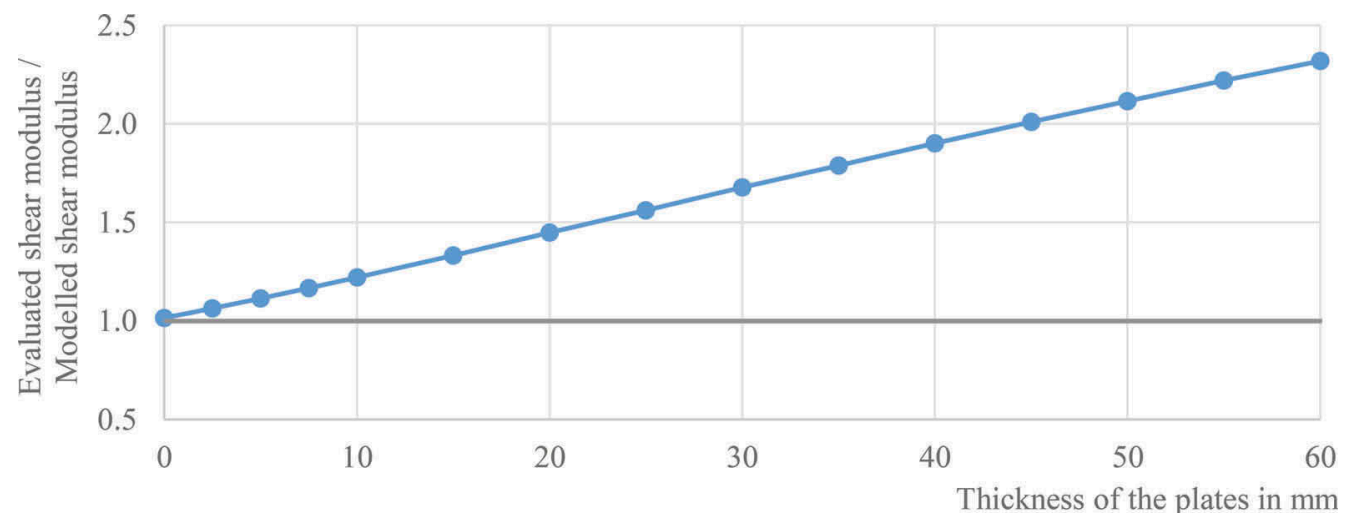

Figure 3. Error of the square tests.

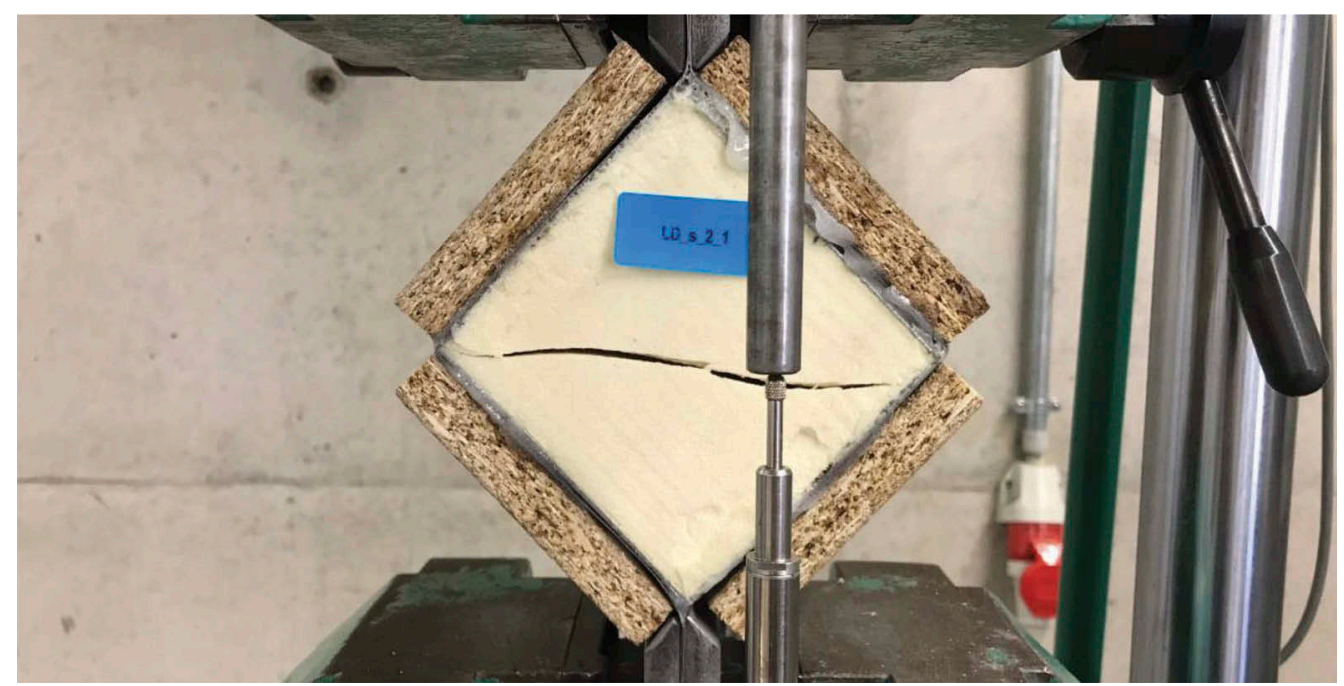

Figure 4. Plastic hinge square shear test - Shear fracture.

stiffness compared to the core material, as well as the face sheets of the specimen. The solution was found in the plastic hinge square shear test.

Instead of thick plates, metal sheets with a thickness of $0.5 \mathrm{~mm}$ are glued on the sides of the square shaped specimen. The frame is split into two cold formed steel sheets on the left and the right side of the specimen. The ends of these sheets are clamped by steel plates in the upper and lower edge of the specimen (Figure 4). To provide a high bending stiffness thick wooden plates are glued on the steel sheets afterwards. The different stiffness resulting from the Young's modulus of steel sheets and the wooden plates provide that the axial forces in the frame are acting in the plane of the steel sheets. So the setup provides that they are acting very close to the surface of the specimen, while the wooden plates prevent the sheets from bending.

After the bending-load capacity is reached plastic hinges develop in the edges of the frame. They prevent that the frame is carrying further loads and following only the specimen is stressed. Because of the thin sheets, the load-bearing capacity of the frame is small, but can still be calculated and taken into account in the test evaluation (Grimm et al. 2020). 
Since the testing principle is similar to the tests with a picture frame fixing according to ASTM D8067/D8067M, the plastic hinge square shear test provides the basis for further detailed research on sandwich-panels core material using digital image correlation measurement systems (DIC). Further studies will be carried out to validate the results of the new test setup. In a first step four-point-bending shear tests where modelled using the shear modulus determined by the plastic hinge square shear test. Deflections in the model show good accordance with the values measured during the associated tests.

\section{STUDIES WITH THE NEW PLASTIC HINGE SQUARE SHEAR TESTS}

The new plastic hinge square shear test was used for different studies. In a project on shell structures made of curved sandwich panels, their shear modulus was determined, as the panel's curvature has little effect on the results because of the small dimensions of the specimen. Furthermore, it was used to assess the shear stiffness and strength of the core of sandwich panels differing from their longitudinal axis.

\subsection{Shear testing of curved sandwich panels}

In the project on curved sandwich panels, a test-procedure for the determination of the material properties of the panel's core was needed. Since an effect of the panel's curvature on the results of the four-point-bending or two- or three-rail shear tests must be assumed, the square shear test seemed to be the most promising setup.

Because of the relatively small dimensions of the square-shaped specimen, its curvature can be neglected. Furthermore, the setup of the square shear test avoids the influence of normal stresses. These result from supporting or loading situations of a bending test or the free edges of two- and three-rail tests. Moreover, DIC measurement systems offer the ability of detailed investigation of the inhomogeneity of the core material. These might be affected by a new production process for curved sandwich panels.

\subsection{Shear testing of sandwich panels differing from the longitudinal axis}

Since the direction of the profiling of the panels face sheets does not affect the results of a square shear test, a preliminary study with tests deviating from the longitudinal axis was conducted. The specimens for this study were cut from sandwich panels with a PIR-core in five different angles including the longitudinal (x-axis or $0^{\circ}$ ) and transverse direction (y-axis or $90^{\circ}$ ). The vertical direction of all specimen was the z-axis. The loading rate was set according to EN 14509 annex A.3.4. Five or three specimen were tested for each direction at room temperature. The shear stresses and deformations were calculated according to Equation (1) und (2).

The shear modulus was determined as:

$$
G=\frac{\tau}{\gamma}
$$

with $\tau$ according to Equation (1) and $\gamma$ according to Equation (2).

The results in Figure 5 show that the shear modulus decreases with growing angle referred to the longitudinal axis of the panel. Only the result for the angle of $22.5^{\circ}$ does not fit into this trend. Deviating from the other orientations the specimen with the $22.5^{\circ}$ direction had a higher initial stiffness, which decreases beyond the distortion of $0.01 \mathrm{rad}$, which was the upper value of the evaluation field that was set the same for all directions. Furthermore, the divergence in the results for the $0^{\circ}$ direction is significantly higher than for the $22.5^{\circ}$ direction.

The results for the ultimate shear strength show a similar trend like the shear modulus. Different from the above, the result for the $22.5^{\circ}$ direction matches the trend. Summarizing, it 


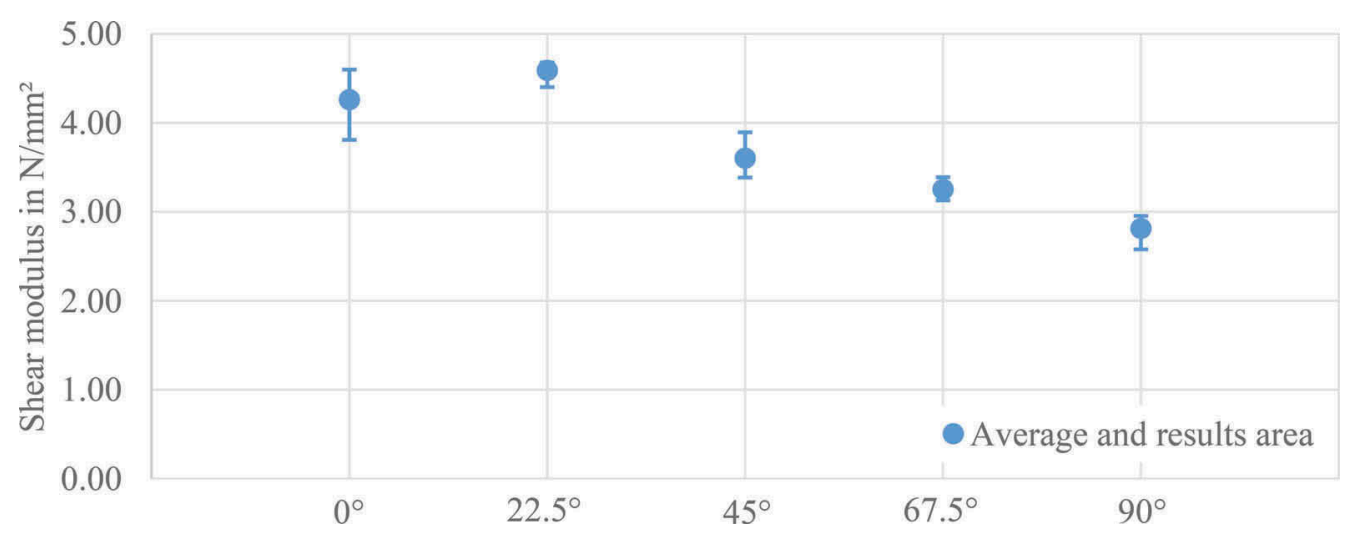

Figure 5. Shear modulus of the PIR-core in different directions.

can be assumed, that the shear stiffness and strength of the core of sandwich panels is optimized for their common use as a beam following their longitudinal axis. These findings might be due to their linear manufacturing process. Further research is planned to examine if these findings can be confirmed for a larger number of specimen and be transmitted to the core materials of other manufacturers as well.

\section{CONCLUSIONS AND OUTLOOK}

A new test setup was developed to investigate the shear stiffness and strength of the core of sandwich panels in all possible planes of interest, regardless from the panel's curvature, dimensions or the profiling of its face sheets. Furthermore, the new test setup offers the opportunity to investigate the inhomogeneity of the core material using digital image correlation measurement systems (DIC). The tests on the PIR sandwich core differing from the longitudinal axis suggests that sandwich panels are optimised for their usual application as a beam structure. In a preliminary study the shear stiffness and strength are reduced with a growing angle towards the longitudinal axis, in exception of the $22.5^{\circ}$ direction.

At the moment the four-point bending shear tests according to EN 14509 annex A.3 is examined similar to the numerical studies on the square shear tests, to validate the results of these tests on theoretical basis. Also further experimental studies are planned to investigate, whether there is a relation between the shear stiffness and strength of the core materials of different manufacturers and the tested angle of direction to reduce the number of tests for future test programs.

\section{REFERENCES}

ASTM D8067/D8067M:2017-01. Standard Test Method for In-Plane Shear Properties of Sandwich Panels Using a Picture Frame Fixture. West Conshohocken: ASTM International.

Grimm, S., Moneke, M., Reising, J., Lange, J., Groche, P., Schäfer, S. 2020. P 1234 Flächentragwerke aus gekrümmten Sandwichelementen. Düsseldorf: FOSTA - Forschungsvereinigung Stahlanwendung e. V.

Davies, J.M. (ed) 2001. Lightweight Sandwich Construction. Oxford et al: Blackwell Science.

EN 14509:2013-10. Self-supporting double skin metal faced insulating panels - Factory made products Specifications. Brussels: CEN European Committee for Standardization.

Jungbluth, O. \& Berner, K. 1986. Verbund- und Sandwichtragwerke: Tragverhalten, Feuerwiderstand, Bauphysik. Berlin: Springer.

Kurpiela, A. 2013. Optimierung von Sandwichwandbauteilen mit PUR-Kern und Stahldeckschichten. Darmstadt: Institut für Stahlbau und Werksto $\square$ mechanik der Technischen Universität Darmstadt. 